\title{
Performance evaluation of different DEMs for topographic correction on LAPAN-A3: preliminary results
}

\section{Zylshal Zylshal}

Zylshal Zylshal, "Performance evaluation of different DEMs for topographic correction on LAPAN-A3: preliminary results," Proc. SPIE 11311, Sixth Geoinformation Science Symposium, 113110K (21 November 2019); doi: $10.1117 / 12.2543437$

SPIE Event: Sixth Geoinformation Science Symposium, 2019, Yogyakarta, Indonesia 


\title{
Performance evaluation of different DEMs for topographic correction on LAPAN-A3: A preliminary results
}

\author{
Zylshal Zylshal $^{\mathrm{a}}$ \\ ${ }^{a}$ Remote Sensing Data and Technology Center, \\ Indonesian National Institute of Aeronautics and Space (LAPAN), \\ Jl. LAPAN No.70, Pasar Rebo, Jakarta Timur, Indonesia. 17310
}

\begin{abstract}
Topographic correction over the mountainous region is an essential preprocessing step for landuse/landcover extraction from earth observation (EO) satellite data. Until the time of this paper writing, there has not been any publication regarding topographic correction on LAPAN-A3 multispectral data. Topographic correction mainly grouped into two categories: band ratio and illumination modeling which required ancillary digital elevation model (DEM). This paper aims to evaluate three different DEM sources used for topographic correction on LAPAN-A3. These DEMs are Shuttle Radar Topographic Mission (SRTM), ALOS World 3D (AW3D), and nation-wide DEMNAS. The topographic corrections were performed over a subset of forested mountainous region in South Sulawesi, Indonesia. Minnaert correction algorithm was used in all three DEMs and evaluate the results. Performance evaluation was based on visual assessment, as well as spectral homogeneity of the pixel value before and after correction. The spectral homogeneity was calculated based on coefficient variation changes before and after correction. The initial results showed that SRTM produced the best visual appearance, while AW3D 30 performed the best in terms of highest reduction in coefficient variation.
\end{abstract}

Keywords: LAPAN-A3, Topographic Correction, Minnaert, SRTM, AW3D, DEMNAS

\section{INTRODUCTION}

The topographic effect on the mountainous region creates illumination discrepancies among different facing slopes, resulting in different spectral responses ${ }^{1}$. The same object on different facing slopes could have different spectral values on the EO satellite data. This hampers our ability to accurately map the landuse/landcover (LULC), or performing consistent and accurate vegetation monitoring. This problem has long been acknowledged, and several studies have been conducted to minimize the aforementioned effect. Several studies have tested and applied these techniques on various datasets. ${ }^{1-9}$ were using Landsat data (from MSS to OLI). ${ }^{10,11}$ were performing the topographic correction on IKONOS data. Generally, there are two types of topographic correction methods. First, using band ratios, and second, using Digital Elevation Models (DEMs) ${ }^{1}$. Band ratio ${ }^{12}$ reduces the radiometric resolution and therefore was excluded in this initial study. The second approach utilizes DEM to reconstruct the different illumination on the earth's terrain based on slope, aspect, and sun position ${ }^{13}$.

There have been numerous proposed algorithm on utilizing the DEM to topographic correction. ${ }^{2,14}$ neatly summarize some of the widely-used topographic correction. Among these algorithms, Minnaert correction ${ }^{15}$, first introduced in 1941, is one of the most cited algorithms in topographic correction, has been chosen to achieve the research's objective. The previous study has been conducted to see how different resolution of DEM could affect the algorithm's performance. In the past, high-resolution DEM data is expensive and difficult to obtain by the researchers ${ }^{8}$. Therefore, the global $90 \mathrm{~m}$ SRTM has been widely used in aforementioned EO data. How well it performed to the LAPAN-A3 data is yet to be answered. Another global elevation data, available for free, is the ALOS World 3D 30 meter (AW3D30). Since the data only just released for public in 2017, it is interesting to see how well it performed when used in topographic correction. And last recently, Indonesian Geospatial Agency (Badan Informasi Geospasial, BIG) released nation-wide high-resolution DEM data called DEMNAS. With spatial resolution of $8 \mathrm{~m}$, this data represents the higher spatial resolution compared to the previously mentioned DEM. Thus, give us a complete range of spatial resolution.

Launched in June 2016, the LAPAN-A3/LAPAN-IPB satellite carries multiple payloads. Among them, a specific sensor called Line Imager Space Application (LISA) was designed to monitor the earth's resources, specifically for forest and

Sixth Geoinformation Science Symposium, edited by Sandy Budi Wibowo, Andi B. Rimba

Stuart Phinn, Ammar A. Aziz, Proc. of SPIE, Vol. 11311, 113110K · C 2019 SPIE

CCC code: $0277-786 \mathrm{X} / 19 / \$ 21 \cdot$ doi: $10.1117 / 12.2543437$ 
agriculture. LISA consists of four bands, ranging from visible to near-infrared spectrum ${ }^{16}$. With its 15 meters spatial resolution and $123 \mathrm{~km}$ swath width, it falls perfectly in the range of medium resolution EO satellite. These types of coverage and spatial resolution deemed perfect for monitoring the earth's surface. Forest monitoring is one of the suitable application. But, as briefly mentioned before, it is sometimes disrupted by the topographic effect, especially in mountainous regions. Until the writing of this paper, there has not been any extensive study or publication on LAPAN-A3 regarding topographic correction. Most research on LAPAN-A3 was focusing on the spectral or the radiometric correction ${ }^{16-19}$, or landuse/landcover mapping ${ }^{20-23}$. This paper presents the initial results on how three different DEM performed when used for topographic correction.

\section{DATA AND METHODS}

\subsection{Study Area}

This study was conducted in a subset of a $23 \times 23 \mathrm{~km}$ area in South Sulawesi, further referred to as the area of interest (AOI). The AOI is laid on an old volcanic region, specifically on Baturappe - Cindakko volcanic rock formation (Tpbv). The landscape is dominated by forest and agriculture landcover, with undulating relief forming a circular pattern. The relatively flat area is also visible in southwest region, near the left bottom of the rectangular shown in figure 1 . The combination of slopped and flat area is essential to evaluate the performance of topographic correction since it can give a more comprehensive variation on the pixel values.

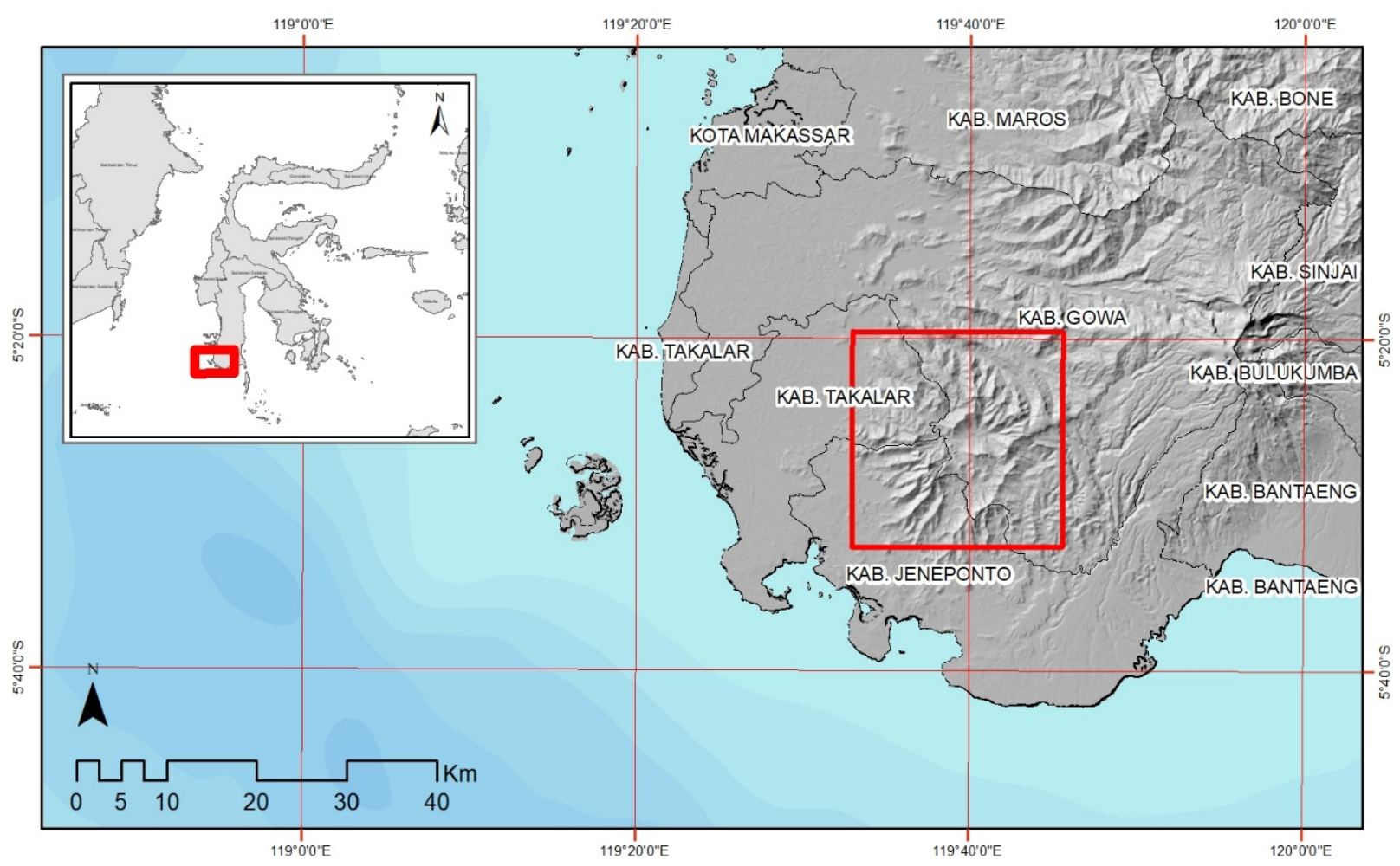

Figure 1. Overview of the Area of Interest (marked by the red rectangle) over South Sulawesi.

\subsection{Digital Elevation Model (DEM)}

DEM represents the 3D information on the ground and is a paramount variable needed for semi-empirical Topographic correction. Shuttle Radar Topographic Mission (SRTM) has been around since 2000 and been widely used for various applications. Among these studies, 1,2,4,6,8,9,14,24-27 were all used SRTM data for correcting the topographic effect on EO Satellite data. 
ALOS World 3D-30m (AW3D30) is the Japan Aerospace Exploration Agency (JAXA) project to provide a global digital 3D map. This project utilized PRISM panchromatic stereo mapping sensors aboard the Advanced Land Observing Satellite (ALOS), which is operated from 2006 to 2011. AW3D30 is a global Digital Surface Model (DSM) with 30 meters spatial resolution and first released on March 201725,28-30.
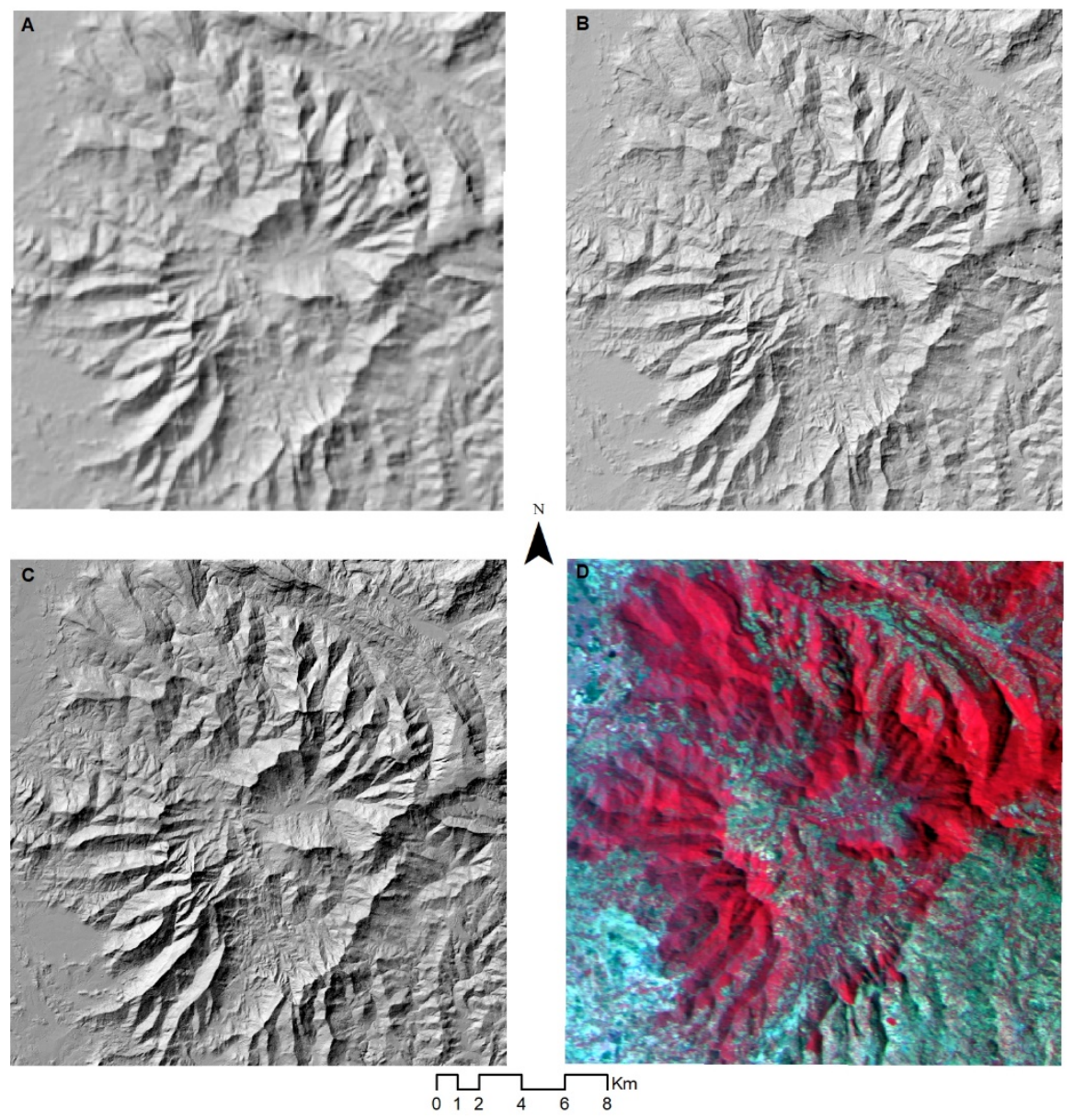

Figure 2. Hillshade of Digital Elevation Model used in this study, (a) SRTM, (b) AW3D, (c) DEMNAS, and (d) False-color composite of LAPAN-A3 data of the same area. Hillshade at the sun azimuth of $315^{\circ}$ and the sun altitude of $45^{\circ}$.

Table 1. Digital Elevation Model Specification used in this study.

\begin{tabular}{|l|l|l|l|}
\hline NO & \multicolumn{1}{|c|}{ DEM } & Spatial Resolution & Vertical Accuracy \\
\hline 1 & SRTM & $90 \mathrm{~m}$ & $<16 \mathrm{~m}$ \\
\hline 2 & AW3D & $25 \mathrm{~m}$ & $5 \mathrm{~m}$ \\
\hline 3 & DEMNAS & $8 \mathrm{~m}$ & $<5 \mathrm{~m}$ \\
\hline
\end{tabular}

9,10,31,32 Previously explained that it is appropriate to use a DEM with a similar grid size as the spatial resolution of the analyzed imagery. In this initial study, three types of DEM with different spatial resolution were analyzed based on their original resolution without prior resampling. Table 1 summarizes the DEMs used in this study. 


\subsection{LAPAN-A3/LAPAN-IPB}

For convenience, LAPAN-A3/LAPAN-IPB will be addressed as LA3 in the further section of this paper. The LA3 data used in this study was acquired on $28^{\text {th }}$ August 2018 at 09.34 AM local time. The sun azimuth was at 69.4437 , with the elevation of 50.7594 .

\subsection{Preprocessing}

The first step of our study started with geometric correction. Fifty 50 ground control points (GCP) were manually selected and used in the geometric correction. Landsat- 8 Tier-1 data were used as the reference using image-to-image correction ${ }^{33}$ methods. Due to the undulating nature of the scene, the geometric correction was performed using the second degree of polynomial ${ }^{34}$. The root means the square error was kept under 1 pixel (15 meters). After the image was geometrically corrected, the next step was to subset all the data using the same AOI boundary, described before. Noticed that, no prior radiometric and atmospheric correction were performed to the LA3 data. The main reason was that at the time of the writing of this paper, the necessary parameters for atmospheric correction was not available yet ${ }^{20}$.

\subsection{Topographic Correction}

The Minnaert algorithm is based on the non-Lambertian reflectance assumption. What makes it different from the Lambertian model is the use of $\mathrm{k}$ constant. This particular $\mathrm{k}$ constant was based on the bidirectional reflectance distribution function. The $\mathrm{k}$ values range from 0 to 1.0 indicates non-Lambertian surface, and 1 indicates a Lambertian surface ${ }^{15}$. The Minnaert algorithm can be expressed with the following formula:

$$
L_{m}=L *\left(\frac{\cos e}{\cos ^{k} i * \cos ^{k} e}\right)
$$

Where,

$L_{m} \quad=$ radiance after correction

$L \quad=$ radiance before correction

$L_{\min } \quad=$ minimum radiance before the correction

$i \quad=$ solar incident angle

$e \quad=$ angle of incidence the sensor received

$k \quad=$ the Minnaert constant

the equation (1) can be rewritten as,

$$
L_{m} *\left(\cos ^{k} i * \cos ^{k} e\right)=L * \cos e
$$

Using both sides of the variable, the equation (1) can be translated as:

$$
\ln L_{m}+k \ln (\cos i * \cos e)=\ln (L * \cos e)
$$

If we consider $\ln L_{m}$ as $m, \ln (L * \cos e)$ as $y$, and $\ln (\cos i * \cos e)$ as $x$, then the equation (3) can be formulated as a linear function of,

$$
y=k x+m
$$

The linear regression function was plotted from the point samples and must be extracted from the same landuse/landcover type $^{35}$. All samples used in this study were taken from the forest region. As the middle ground, $\mathrm{k}$ values were set at 0.5 for all bands since the AOI is a combination of the flat and sloped area as shown in figure 1 .

\subsection{Performance Evaluation}

To evaluate the performance of different DEMs used for topographic correction, visual inspection used to see the difference before and after correction ${ }^{7}$. The next step was to perform quantitative analysis on both before and after topographic correction. The decreased variation coefficient (CV) is a widely used method for validating topographic correction ${ }^{1,9}$. It is also referred to as a test of homogeneity, $3,4,6,9,36,37$. To assess the effectiveness of each DEM, the means and standard 
deviation (SD) were calculated and compared for both before and after correction. Next, the variation coefficient was calculated as well, also referred as Dispersion Indices ${ }^{8}$. For the statistical analysis, 85 sample points were selected on slopped region.

\section{RESULTS AND DISCUSSION}

\subsection{Visual Evaluation}

Figure 2 shows the confirmed effect of the topographic correction on LA3 using all three DEMs. The topographic correction has visibly taken effect on the west and southwest facing slopes. The visual appearance on SRTM gives better results (figure 2a, while DEMNAS and AW3D30 give similar appearances (figure 2b and 2c). Looking closer, some overcorrection was found on DEMNAS and AW3D30, specifically on high slopes and shadowed slopes (greater than $40^{\circ}$ as shown in figure $2 \mathrm{~b}$ and $2 \mathrm{c}$ ).
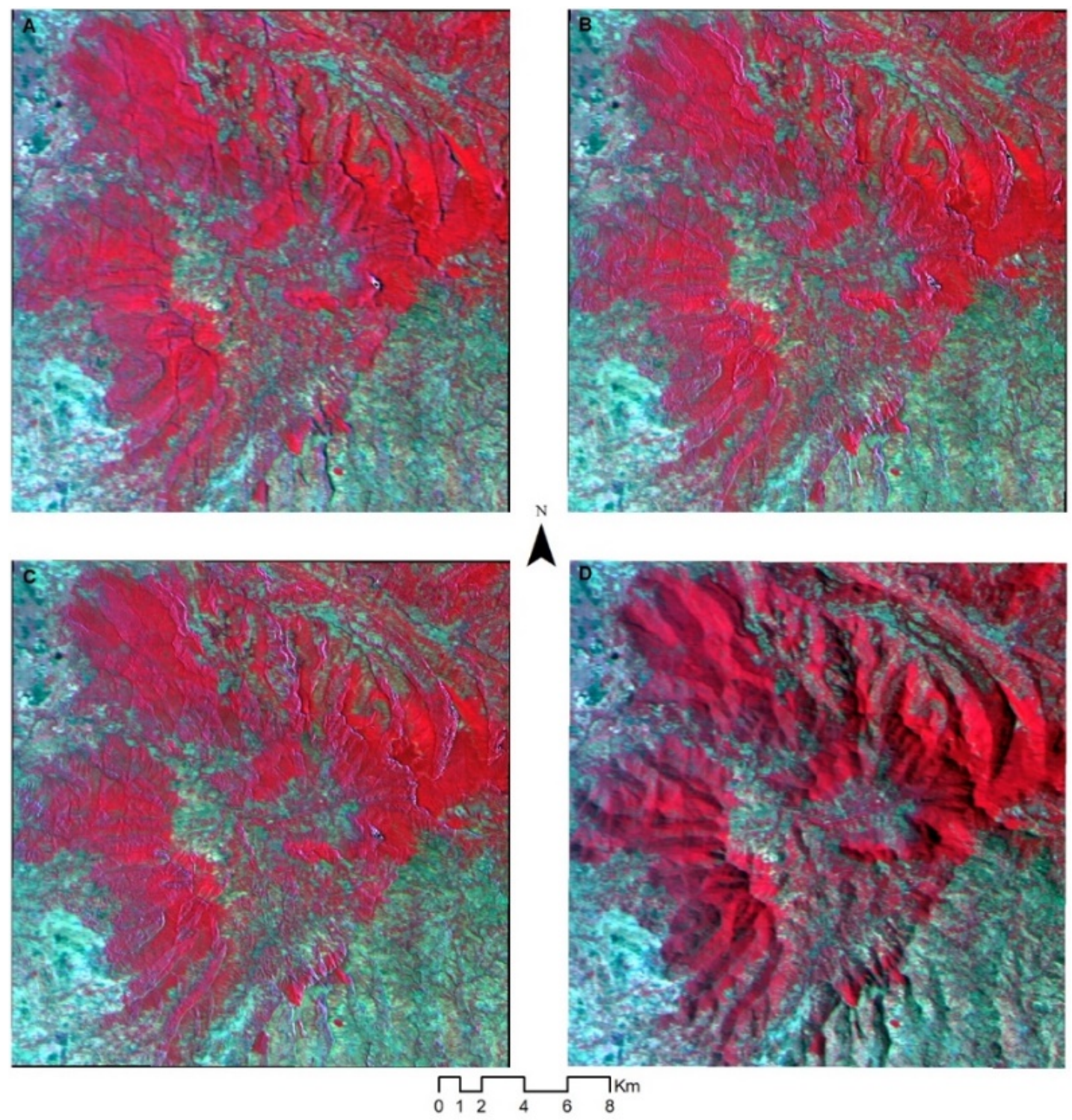

Figure 3. Visual comparison of topographically corrected LAPAN-A3 using Minnaert Correction using different DEM, (a) SRTM, (b) AW3D, (c) DEMNAS, and (d) Original LA3 image. All images are shown in the RGB composite of NIR-R-G. 


\subsection{Quantitative Evaluation}

Table 2 shows the coefficient of variation for each band and each DEM source, including the original and corrected image. Looking at how much CV change after correction, each DEM gives different change in the CV. The best performance, however, is not dominated by a single DEM source. AW3D performed best on both B and R band, while SRTM and DEMNAS performed best for G and NIR bands, respectively. Figure 4a to figure $4 \mathrm{~d}$ shows how all these DEM performed for each band, while $4 \mathrm{e}$ shows the different magnitude of CV changes. A good topographic correction should decrease $\mathrm{CV}$ values $^{6}$. This case only happens for NIR bands. All three DEMs were able to decrease CV value. For the R band, AW3D and SRTM were able to reduce the CV. DEMNAS, however, saw an increase in the CV. The G and B bands were all saw increased CV values after corrected. The initial assessment presented here shows how the topographic correction method produces an increase in $\mathrm{CV}$ value. The increase in $\mathrm{CV}$ values is more common than the reduction of $\mathrm{CV}$. On average, AW3D30 performed the best as it offers an even result between the numbers of bands with CV value was decreased and vice versa. Looking at the number of bands with decreased CV in table 2, it would be easy to point out that DEMNAS performed the worst of all three DEMs, as it was only able to reduce the CV for 1 band (NIR). However, looking at figure 2E, SRTM gave the biggest increase in CV value after corrected. Looking at the graph in figure 2E, SRTM eclipsed other DEM in terms of CV value change. For the B band, SRTM increased the CV up to 196.40, compared to both AW3D and DEMNAS.

Table 2. Coefficient variation and standard deviation for each band before and after topographic correction. A negative value indicates an increase in coefficient variation after correction. Bold CV value marked the best performer.

\begin{tabular}{|c|r|r|r|r|r|r|r|}
\hline \multirow{2}{*}{ Band } & \multicolumn{4}{|c|}{ CV } & \multicolumn{2}{c|}{$\begin{array}{c}\text { CV Difference before and after } \\
\text { correction }\end{array}$} \\
\cline { 2 - 9 } & Original & \multicolumn{1}{|c|}{ SRTM } & \multicolumn{1}{|c|}{ AW3D } & DEMNAS & \multicolumn{1}{c|}{ AW3D } & \multicolumn{1}{c|}{ SRTM } & \multicolumn{1}{c|}{ DEMNAS } \\
\hline B & 507.68 & 704.08 & 509.09 & 510.03 & $-\mathbf{- 1 . 4 1}$ & -196.40 & -2.35 \\
\hline G & 9.55 & 9.68 & 11.76 & 14.38 & -2.21 & $\mathbf{- 0 . 1 3}$ & -4.83 \\
\hline R & 21.72 & 15.54 & 20.87 & 22.07 & 0.85 & $\mathbf{6 . 1 8}$ & -0.35 \\
\hline NIR & 12.11 & 8.41 & 8.88 & 10.75 & 3.23 & $\mathbf{3 . 7 0}$ & 1.37 \\
\hline
\end{tabular}
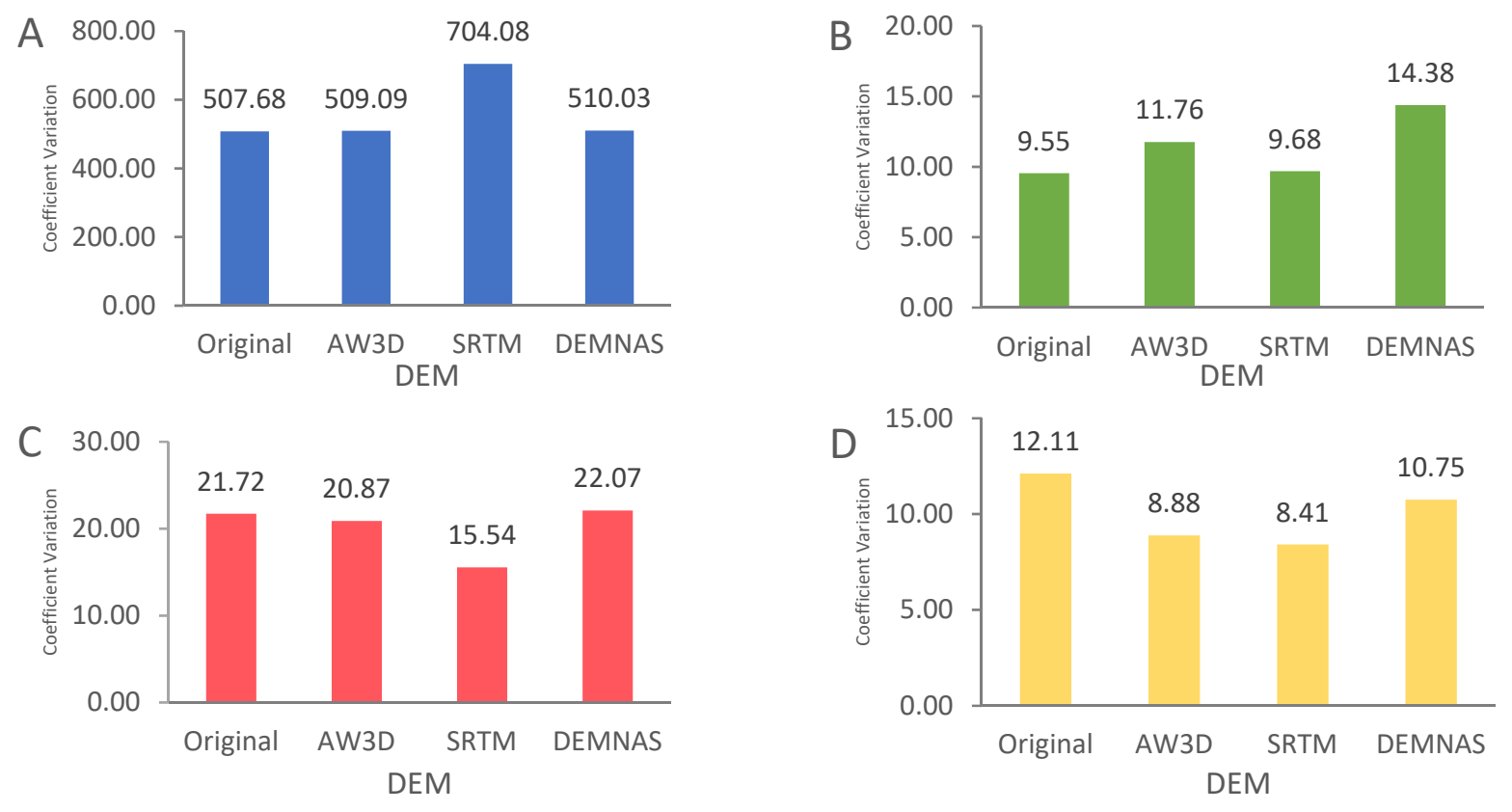


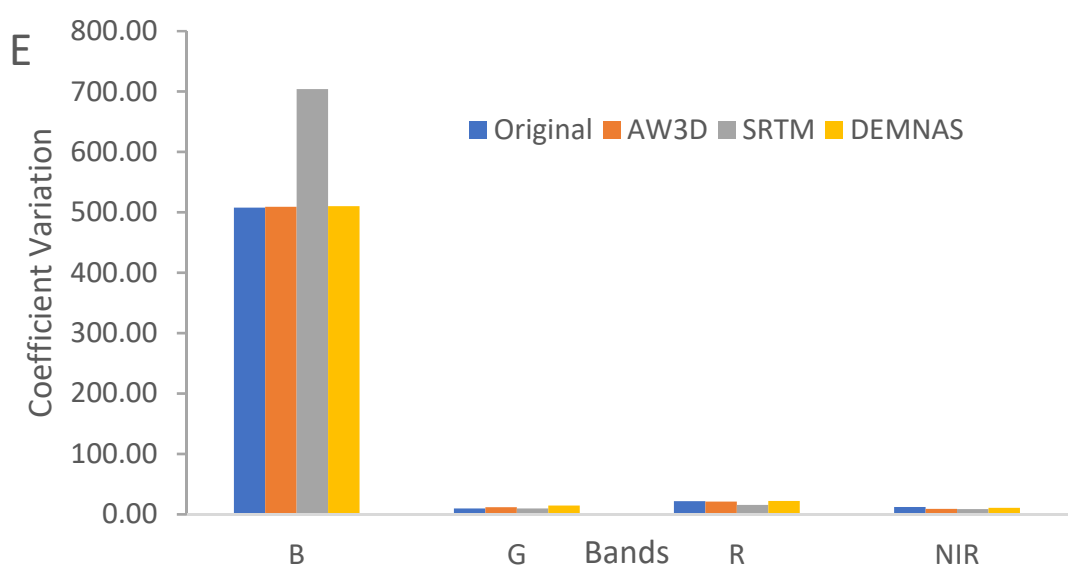

Figure 4. Coefficient correlation for three different DEM compared to the original value. (a) Coefficient variation for Blue band, (b) Coefficient variation for green band, (c) coefficient variation of red band, (d) coefficient variation of Near-Infrared Band, (e) coefficient variation for all bands to show the different magnitude of CV across four different DEMs.

Table 3. Comparison overview for all three DEMs used with the topographic correction performance parameters used in this study. A negative value on the total $\mathrm{CV}$ value indicates an increase in coefficient variation after correction.

\begin{tabular}{|l|l|c|c|}
\hline \multirow{2}{*}{ DEM } & \multicolumn{3}{|c|}{ Parameters Compared } \\
\cline { 2 - 4 } & \multicolumn{1}{|c|}{ Visual Evaluation } & $\begin{array}{c}\text { Number of Bands } \\
\text { with Reduced CV }\end{array}$ & $\begin{array}{c}\text { Total CV Value } \\
\text { reduced for all } \\
\text { bands }\end{array}$ \\
\hline SRTM & No over-correction visible & 2 & -186.65 \\
\hline AW3D 30 & Over-correction visible & 2 & 0.46 \\
\hline DEMNAS & Over-correction visible & 1 & -6.16 \\
\hline
\end{tabular}

Table 3 shows the comparison parameters for all three DEMs used. The overall better performer is the AW3D, with the most number of bands reduced, and the only DEM source to give positive value on total CV reduced for all bands. While SRTM gave the same amount of bands with reduced CV and a better visual appearance, its total CV changed after correction with the magnitude of more than 400 times the best performer is just too much. The AW3D performance has also been a nod to how earlier findings of ${ }^{6,9}$ explained that for topographic correction based on modeling of illumination, the same spatial resolution between DEM and the investigated image is required. Thus, the next plan of this study is to see how these DEMs performed when its spatial resolution is at the same size.

The success in CV reduction for the NIR band found in this study is consistent with what ${ }^{6}$ previously found, who found the reduction on CV for the vegetation-sensitive band (NIR and SWIR of Landsat TM-5). Since no prior radiometric/atmospheric correction was performed to LA3 data, the fact that NIR band is the least affected by atmospheric conditions compared to $\mathrm{B}, \mathrm{G}$, and $\mathrm{R}$ band ${ }^{16}$ is also a factor to how the topographic correction could be performed well. Therefore, it is vital to investigate further how the topographic correction performed when prior radiometric/atmospheric correction was conducted.

\section{CONCLUSIONS}

In this preliminary study, three DEMs were selected and tested to perform topographic correction on LAPAN-A3 data using Minnaert Correction. SRTM gave the best visual appearance, while AW3D performed the best in terms of reduction in coefficient variation. The topographic correction performed differently on different bands. All three DEMs were able to reduce the CV on the NIR band. 
Future research should be focusing on performing a different algorithm, as well as using the same size pixel for all three DEMs. Classification accuracy should also be included in performance evaluation. Different AOI with different landforms should also be further investigated.

\section{ACKNOWLEDGMENT}

This study conducted with the full funding support from Remote Sensing Data and Technology as well as the Remote Sensing Ground Station Parepare. The research is part of a bigger project on haze and cloud removal developed by LAPAN through INSINAS Project 2019. The author also would like to thank LAPAN Satellite Technology Center for its support regarding LAPAN-A3 data used in this study.

\section{REFERENCES}

[1] Gao, Y. and Zhang, W., "A simple empirical topographic correction method for ETM + imagery,” Int. J. Remote Sens. 30(9), 2259-2275 (2009).

[2] Vanonckelen, S., Lhermitte, S., Balthazar, V. and Van Rompaey, A., "Performance of atmospheric and topographic correction methods on Landsat imagery in mountain areas," Int. J. Remote Sens. 35(13), 4952-4972 (2014).

[3] Riaño, D., Chuvieco, E., Salas, J. and Aguado, I., "Assessment of different topographic corrections in landsatTM data for mapping vegetation types (2003)," IEEE Trans. Geosci. Remote Sens. 41(5 PART 1), 1056-1061 (2003).

[4] Phiri, D., Morgenroth, J., Xu, C. and Hermosilla, T., "Effects of pre-processing methods on Landsat OLI-8 land cover classification using OBIA and random forests classifier," Int. J. Appl. Earth Obs. Geoinf. 73(April), 170178 (2018).

[5] Leprieur, C. E., Durand, J. M. and Peyron, J. L., "Influence of topography on forest reflectance using Landsat Thematic Mapper and digital terrain data," Photogramm. Eng. Remote Sensing 54(4), 491-496 (1988).

[6] Pimple, U., Sitthi, A., Simonetti, D., Pungkul, S., Leadprathom, K. and Chidthaisong, A., "Topographic correction of Landsat TM-5 and Landsat OLI-8 imagery to improve the performance of forest classification in the mountainous terrain of Northeast Thailand," Sustain. 9(2), 1-26 (2017).

[7] Civco, D. L., "Topographic Normalization of Landsat Thematic Mapper Digital Imagery," Photogramm. Eng. Remote Sensing 55(9), 1303-1309 (1989).

[8] Gao, Y. and Zhang, W., "LULC classification and topographic correction of Landsat-7 ETM+ Imagery in the Yangjia river Watershed: The influence of DEM resolution," Sensors 9(3), 1980-1995 (2009).

[9] Hantson, S. and Chuvieco, E., "Evaluation of different topographic correction methods for landsat imagery," Int. J. Appl. Earth Obs. Geoinf. 13(5), 691-700 (2011).

[10] Nichol, J. and Hang, L. K., "The Influence of DEM Accuracy on Topographic Correction of Ikonos Satellite Images," Photogramm. Eng. Remote Sens. 74(1), 47-53 (2013).

[11] Law, K. H. and Nichol, J., "Topographic correction for differential illumination effects on ikonos satellite imagery," XXth ISPRS Congr. XXXV Part, 641-646 (2004).

[12] Chavez Jr., P. S., "Image-Based Atmospheric Corrections - Revisited and Improved," Photogramm. Eng. Remote Sens. 62(10), 1025-1036 (1996).

[13] Balthazar, V., Vanacker, V. and Lambin, E. F., "Evaluation and parameterization of ATCOR3 topographic correction method for forest cover mapping in mountain areas," Elsevier B.V. (2012).

[14] Vanonckelen, S., Lhermitte, S. and Van Rompaey, A., "The effect of atmospheric and topographic correction methods on land cover classification accuracy," Int. J. Appl. Earth Obs. Geoinf. 24(1), 9-21 (2013).

[15] Minnaert, M., "The reciprocity principle in lunar photometry," Astrophys. J. 93(2), 403-410 (1941).

[16] Zylshal, Z., Sari, N. M., Nugroho, J. T. and Kushardono, D., "Comparison of Spectral Characteristic between LAPAN-A3 and Sentinel-2A,” IOP Conf. Ser. Earth Environ. Sci. 98(1), 012051 (2017).

[17] Tahir, A. M., Hakim, P. R., Syafruddin, A. H., Cagak, J., Km, S. and Indonesia, B., "Image-Focusing Quality Improvement on Lapan-A3 Satellite Multispectral Imager," J. Teknol. Dirgant. 14(1), 37-50 (2016).

[18] Hakim, P. R., Syafrudin, A. H. and Utama, S., "Band Co-registration Distortion Modeling of LAPAN-A3 Multispectral Imager Based on Satellite Attitude," 4th Int. Symp. LISAT 2017 (2017). 
[19] Hakim, P. R., Hasbi, W. and Syafrudin, A. H., “ADCS requirements of Lapan-A3 satellite based on image geometry analysis,” Proceeding - ICARES 20142014 IEEE Int. Conf. Aerosp. Electron. Remote Sens. Technol., 142-146 (2014).

[20] Zylshal, Z., Wirawan, R. R. and Kushardono, D., "Assessing the Potential of LAPAN-A3 Data for Landuse/landcover Mapping,” Indones. J. Geogr. 50(in review), 184 (2018).

[21] Setiawan, Y., Prasetyo, L. B., Pawitan, H., Wijayanto, A. K., Permatasari, P. A., Syartinilia and Liyantono., “An Evaluation of the Use of Lapan-A3/IPB Spectral Features to Identify Agricultural Land Use Types in Java, Indonesia," 4th Int. Symp. LISAT 2017, Bogor, Indonesia (2017).

[22] Nugroho, J. T., Zylshal, Z. and Kushardono, D., "LAPAN-A3 Satellite Data Analysis for Land Cover Classificationb (Case Study: Toba Lake Area, North Sumatra),” Int. J. Remote Sens. Earth Sci. 15(1), 71-80 (2018).

[23] Setiawan, Y., Prasetyo, L. B., Pawitan, H., Liyantono, L., Syartinilia, S., Wijayanto, A. K., Permatasari, P. A., Syafrudin, A. H. and Hakim, P. R., "Pemanfaatan Fusi Data Satelit Lapan-a3/Ipb Dan Landsat 8 Untuk Monitoring Lahan Sawah,” J. Pengelolaan Sumberd. Alam dan Lingkung. (Journal Nat. Resour. Environ. Manag. 8(1), 67-76 (2018).

[24] Samsonov, S., "Topographic correction for ALOS PALSAR interferometry," IEEE Trans. Geosci. Remote Sens. 48(7), 3020-3027 (2010).

[25] Takaku, J., Tadono, T., Tsutsui, K. and Ichikawa, M., "Validation of 'Aw3D' Global Dsm Generated From Alos Prism,” ISPRS Ann. Photogramm. Remote Sens. Spat. Inf. Sci. III-4(July), 25-31 (2016).

[26] Gao, M., Gong, H., Zhao, W., Chen, B., Chen, Z. and Shi, M., "An improved topographic correction model based on Minnaert," GIScience Remote Sens. 53(2), 247-264 (2016).

[27] Takaku, J. and Tadono, T., "Quality updates of 'AW3D' global DSM generated from ALOS PRISM,” 2017 IEEE Int. Geosci. Remote Sens. Symp., 5666-5669 (2017).

[28] JAXA., “ALOS Global Digital Surface Model ( DSM ) ' ALOS World 3D-30m ' ( AW3D30 ) Dataset Product Format Description Earth Observation Research Center ( EORC), Japan Aerospace Exploration Agency ( JAXA )" (2017).

[29] Japan Aerosapce Exploration Agency, E. O. R. C., "ALOS Global Digital Surface Model 'ALOS World 3D 30m (AW3D30)' - Product Description,” Japan Aerosp. Explor. Agency(2.2) (1997).

[30] Tadono, T., Nagai, H., Ishida, H., Oda, F., Naito, S., Minakawa, K. and Iwamoto, H., "Generation of the 30 MMESH global digital surface model by alos prism," Int. Arch. Photogramm. Remote Sens. Spat. Inf. Sci. - ISPRS Arch. 41(July), 157-162 (2016).

[31] Kawata, Y., Ueno, S. and Kusaka, T., "Radiometric correction for atmospheric and topographic effects on landsat mss images," Int. J. Remote Sens. 9(4), 1-2 (1988).

[32] Goyal, S. K., Seyfried, M. S. and O'Neill, P. E., "Effect of digital elevation model resolution on topographic correction of airborne SAR," Int. J. Remote Sens. 19(16), 3075-3096 (1998).

[33] Jensen, J. R., [Introductory Digital Image Processing: A Remote Sensing Perspective, 3rd Ed.], Pearson Education (2005).

[34] Danoedoro, P., [Pengantar Penginderaan Jauh Digital, I], Penerbit ANDI, Yogyakarta (2012).

[35] Gao, M., Zhao, W., Gong, Z., Gong, H., Chen, Z., Tang, X., Vi, C. and Vi, W. G., "Topographic Correction of Zy-3 Satellite Image and Its Effects on" (2011).

[36] Conese, C., Gilabert, M. a, Maselli, F. and Bottai, L., "Topographic Normalization of Tm Scenes Through the Use of an Atmospheric Correction Method and Digital Terrain Models," Photogramm. Eng. Remote Sensing 59(12), 1745-1753 (1993).

[37] Ghasemi, N., Mohammadzadeh, A. and Sahebi, M. R., "Assessment of different topographic correction methods in ALOS AVNIR-2 data over a forest area," Int. J. Digit. Earth 6(5), 504-520 (2011). 